\title{
Article
}

\section{Political Correctness: Implosion of Politics}

\author{
Alexis Dirakis \\ Centre Marc Bloch, 10117 Berlin, Germany; ald@cmb.hu-berlin.de \\ Received: 25 May 2017; Accepted: 3 August 2017; Published: 8 August 2017
}

\begin{abstract}
The purpose of this article is to develop a critical understanding of political correctness as regressive process of incrimination based on a utopia of non-differentiation. According to our hypothesis, this utopia represents the ideological product of a double process of identity dissolution under the impact of abstract universalism and contemporary individualism which leads to the implosion of politics.
\end{abstract}

Keywords: political correctness; modern utopia; social radicalism; communitarianism

\section{Introduction}

Political correctness is both one of the most singular and most significant phenomena of contemporary Western societies. A phenomenon that accompanies the expansion of globalization not without causing, like the latter, a set of counter reactions-from simple perplexity to the mostradical opposition.

Despite its growing importance and contestations, political correctness' specific motivation and logic remain ambiguous, obscure, uncertain, and rarely explicit. It belongs to those phenomena that without leaving anyone indifferent and despite their impact, nonetheless elude their immediate understanding.

Political correctness is all the more influential as it imposes as false evidence, is all the more coercive as it condemns oppression, all the more sure of its justification as it denies any bias, all the more irrecusable as it is blind to its own mechanism, all the more powerful as it refuses to acknowledge its power, and all the more discreet as it never utters its name. Finally, it is even more obscure as it extends to all social life: as a political issue, historical consciousness, moral injunction, legal power, ideology, culture, mode of perception, and of appreciation of reality.

A critical understanding of political correctness, positive and negative, is in this sense a major challenge as it reveals our own ideological and political singularity.

\section{Censorship}

Political correctness primarily shows itself in the form of a prohibition. It is a censorship, a moral one currently being judicialized, and is as such doubly coercive. Unlike the familiar and civilized form of self-censorship which is politeness and forbids in the first place pejorative judgments on others, political correctness condemns real or perceived denigration of a group and its members. ${ }^{1}$ It represents a precaution to human groupings - and more specifically towards people associated with them insofar as the reality of those groupings can be contested by the censor. Political correctness is, in other words, a precaution to groups of people that has become a precaution of language.

1 In this sense, political correctness can be considered-and for good reason-as a positive evolution of mores in the sense of a promotion of democratic values: as tolerance of social and cultural diversity, as respect for human dignity, equality and equity between groups, etc. which explains its international success. This point of view is especially relevant as an ethical and moral one on a personal or inter-individual level. However, the purpose of this paper is to focus on political correctness on a political and social level in order to highlight its negative and counterproductive effects. 
Political correctness operates as censorship in various forms-subjectively (through taboos and self-censorship), inter-subjectively (through peer pressure and moral condemnation) and objectively (i.e., formally and compelling through laws, regulations, instructions, etc.). It applies to a set of subjects that can be divided in various levels:

(1) Judgments considered defamatory to a group: preconceived ideas related to its level of intelligence, civility, hygiene, humanity, goodwill, etc.;

(2) Judgments considered defamatory because of their mere generalizing nature, due to the stereotypical perception of a group they express, along the lines of: "This behavior is typical of a [member of group X]", "[Members of group X] are naturally gifted for this sport or activity", etc. Stereotyping is regarded as a form of reductionism, essentialization, ethnicizing, or even biologizing the target group;

(3) Naming of a group deemed disparaging, which will be substituted by a neutral name or one considered to be more decent, for instance "hearing-impaired" for "deaf", "culture" for "ethnic group", "undocumented people" for "illegal immigrants", "homeless" for "tramp" or "vagabond", etc.;

(4) Finally, naming a group whose existence is contested. For example, while USA classifies its citizens according to race the mere use of such terms could be subject to criminal penalty in France. In this (fourth) case, it is not necessary for the censor to acknowledge this group's existence for the condemnation to take place.

\section{Regressive Process of Incrimination}

The list of incriminating events reveals the logic of step-by-step criminalization. This logic primarily points at depreciation, belittling, denigrating, extending to the lower level of stereotyping, biological and sociological categorizing to finally reach the sole naming as verbal recognition of the existence of a group.

Political correctness operates through condemnation, euphemisms (tendentially forms of denial), as well as prevention. In this way, it is not solely censorship but also 'speech therapy' on account of its willingness to correct our perception and appreciation of reality by means of language correction, based on a linguistic constructivism according to which the boundaries of reality coincide with the boundaries of the sayable. ${ }^{2,3}$

\section{Politicization by Suspicion}

The censor of political correctness responds to the generalizing dimension of a deprecatory judgment or solely the naming of a group by another form of generalization. The censor detects behind the generality of a neutral, negative, or rude judgment or naming the aspiration, incitement, or effective contribution to a political agenda. In that sense, political correctness proceeds by an external politicization of statement or naming - whatever their own reason or motivation are. This forced politicization is justified by the recognition - within utterances of certain generalities about groups-of a more or less conscious involvement in harmful ideologies and political radicalism. It will also be legitimized on account of the conviction that free and uncontrolled spreading of such utterances could exacerbate public debate and irreversibly divide society, etc.

2 This principle can be summarized as follows: if you cannot name a thing, this thing cannot exit. Which can also means on a political level: if you want to-but cannot—solve a problem, just stop naming it.

3 Here I agree with Lorenzo Magnani that political correctness tends to "omittive behaviors" and "ostrich effect" and to that extent "often creates a kind of indirect silence about important concrete and important moral situations because of an excess of idealization and abstraction regarding minor issues, which play a strong distracting role". In [1]. 
Because it is driven by the suspicion of hostility towards groups and minorities, its overt vigilance tendentiously leads political correctness to politicize all generalities about groups as ideologically prejudiced.

\section{Where Saying Equals Doing}

The zeal that political correctness shows as censorship and its political and legal importance seem strikingly disproportionate to its primary concern: hostility towards groups which does not refer to physical but exclusively to verbal and often presumed violence.

This glaring disproportion does not however prevent political correctness' determination for which saying equals doing. ${ }^{4}$ Indeed, this performative understanding obscures the distinction between words, ideologies, political projects and their effective implementation. Needless to say that this confusion between words and acts strengthens its determination and ultimately justifies the external politicization of general statements and judgments.

Political correctness thus relates to a psychologizing ontology (a reduction of being-that which is - to thoughts and ideas) that equates the presumed or actual violence of words with acts, speech acts with physical acts-thereby justifying its condemnation as such. It represents, in other words, an anticipatory censorship, denunciation based on simulation, condemnation based on suspicion.

Its performative understanding even tends to erase the distinction between spontaneous and thoughtful, improvised and pre-meditated, naive and planned, and-on another but connected level-between trivial and scandalous, common and tragic, banal and evil.

The performative understanding can justify the use of physical and material constraints as response to a speech act interpreted as a physical act. In such a case, the principle of equating a speech act with a real act, symbolic violence with physical violence amounts to a logic of radicalization, resulting in a non-differentiating to the worst (une indifférenciation vers le pire) for the purpose of its censoring and its condemnation as such.

\section{Unilateral Non-Differentiating}

The relation political correctness has with the social groups it aims to defend, is ambivalent. In the majority of cases (in cases 2 to 4 in Section 2) it pretends not to acknowledge the existence of homogenous, singular, and delineated groups; groups with specific, general, and identifiable traits with the noteworthy exception of groups with their own claim of identity. In this sense, political correctness is censorship through social non-differentiating or more precisely one-sided non-differentiating. The groups manage to escape the logic of indifference only by asserting their own identity. In other words, they can be said to exist only for themselves, not per se or by an exterior identification which would be foreign to them. ${ }^{5}$

The obligation to recognize a claimed identity is as categorical as its denial in the absence of any claim. However, this recognition of a claimed identity does not imply that it allows external or foreign judgment or naming. The public recognition of an identity does not make it a public matter. Groups exist publicly only for themselves. Even in the case of social recognition of a group, its existence is paradoxically denied or concealed unless it is encouraged, permitted, or required by said group as an object to be claimed.

4 To some extent, a speech can be understood as an act, as a "performative utterance" (J.L. Austin). However, in this paper, I prefer not to consider speech as such since that would make the distinction between speech act and physical act necessary and by doing so would only remove the original distinction to a new one (without going beyond it). For example, if we consider the most extreme violent forms of speech (insult and threat) and of act (killing), a substantial difference between them is undeniable. To that extent, I believe it is appropriate to maintain this distinction in the context of our analysis.

5 For instance, in some countries like France, only black people are allowed to use the word "blacks" ("noirs"). Another example: if your colleague comes out as "gay", that does not mean you are allowed call him "gay". In these cases, minorities have a monopoly over their identity and their naming, which do not and must not officially exist for the majorities. 


\section{Militant Apoliticism}

The sociological thinking—even in its "spontaneous" or "wild" form (Pierre Bourdieu)—is based on the ability to differentiate the social world, recognizing its actual fragmentation into self-referential and homogenizing units within the society. On the contrary, political correctness as non-differentiating censorship contests any difference, any diversity, flatters and promotes their denial.

Needless to say that-as obstacle to the intelligibility of the world-this censorship harms enlightened and thoughtful guidance of collective, i.e., political action.

Furthermore, although political correctness operates through politicizing utterances, it remains as censorship and moral judgment, apolitical. The development and realization of true political projects based on its principles is rarely taken into account. It displays a greater concern for the moral order of the world than its state. The distinction between these two orders of reality is de facto clouded by its primary consideration of the register of utterances in order to reform reality through the reform of language.

Without explicit principle or concrete project, political correctness distinguishes itself by its negative and exclusively disapproving mechanism. It is a censorship without a doctrine, a morality ex negativo, an ideology, not a political but a depoliticized one, in other words, a militant apoliticism.

\section{History's Lesson}

The criticism of political correctness is even more difficult and delicate because it is based on today's dominant interpretation of modern history that it aims to be the logical translation in morale and politics of. It serves this historical memory to make better use of its preeminence.

As such, political correctness considers itself as the lesson of history, and of its worst episodes: slavery, colonialism, and Nazism (communist totalitarianism receiving favorable treatment). The intrinsic complexity of these three historical episodes is reduced and amalgamated into a single logic: the oppression of minorities.

As historical consciousness associated with a protective function, political correctness merges with the alertness in respect of a possible comeback of the worst. Its zeal therefore has to be proportional to the violence it wants to eradicate. The threat of this motivates the will to restrict the sayable (as a restriction of reality) and the additional radicalization of utterances (by external politicization and performative understanding of it).

As a corrective and prophylactic response to the evils of humanity, political correctness is seen as a redemption: it aspires to save humanity from the temptation of the worst, embryonic or subconscious as it may be. The immensity of the task is compensated for by the consolation of its redemptive goal.

\section{The Nazification of History}

In historical references to slavery, colonialism, and Nazism, the latter at least in Europe guides the interpretation of history, supported and propagated by political correctness. This reductionist rereading is resultant from the present interpretation and memory of Nazi oppression. In other words, political correctness is based on a semiology of memory comprising —if we may say so-the nazification of the history of minorities: a conflation of various historical forms of persecution and the Nazi one in particular.

This logic of conflation does not end with nazification only being oppression per se, it leads to what Jean-Michel Chaumont [2] satirically calls the "competition among victims' groups for the award of the greatest sufferings". Paradoxically, this "macabre bidding" motivated by the so-called reductio ad Hitlerum (Leo Strauss) ultimately tends toward a relativization of Nazi crimes insofar as the "memory activists" (Esther Benbassa [3]) aim in their unbridled competition at "maximization" of their victimhood for the claim of absolute suffering. 


\section{A Selective Indignation}

Despite its protective function and the radical meticulousness of its processes, political correctness cannot be concerned with every minority. The oppression, even present, of some minorities may be overlooked, denied, or tolerated. Its consideration will depend on the minority's capacity to politicize its present or past oppression and on its ability to keep its memory publicly alive, in other words on its ability to raise the level of compassion and to enforce the moral debt owed by the majority.

This political action not only reinforces the culture of repentance; at a certain level of generalization it inaugurates a new form of culture rather difficult to qualify: minority pluralism, victimhood culture, communality of suffering ... but its importance cannot be overemphasized as it marks a real changeover in the history of collective narcissism around which societies are traditionally structured. At this stage, the minority enjoys such a status that its demands can be met without exacerbating the-taken for granted-guilty conscience of the majority. Moreover, this foresight may in some cases even forestall minority claims.

Political correctness is biased, its indignation in respect of minorities is selective for a second, logical reason: it cannot on principle consider all past and present minority sufferings, even less so since political correctness contributes to a proliferation of victim's claims. In that sense, political correctness foments certain forms of resentment toward the majority but also between minorities due to them being unequally considered.

\section{Transcendentality of the Worst}

The superlative dimension of the object of denunciation, the worst, its absolute character, tendentiously gives political correctness a transcendental dimension. It tends to condition the perception and moral, aesthetic, political, but also libidinal assessment of the world.

Political correctness is a mode of being both in the world and in oneself and a specific mode of constituting and experiencing the two realities of world and self. The oppression of minorities represents the primal scene and matrix of fundamental distinctions between among others, good and evil, right and wrong, just and unjust, the desirable and the repulsive, the healthy and the pathological.

Political correctness marks out the boundaries of human existence, conditions its individual and collective forms, orients its representations and its ethical, aesthetic, political, associative, sexual, artistic, touristic, and gastronomic practices. To that extent, political correctness is not only censorship, morality, or prevention, but a culture.

\section{Absolutization by Desubstantialization}

As censorship and linguistic custodianship in respect of groups or minorities keeping the memory of their oppression alive, political correctness is not made up of the fight against effective, physical, politically encouraged, and collectively exercised persecution of minorities. If political correctness signifies the end of oppression, it has paradoxically established itself in peacetime, its fight coming after the war; nevertheless, it opens up a new battle this time on the issues of mores, values and language.

As mentioned, political correctness tends to consider the oppressive logic all the way back to discrimination by naming groups, suspecting that naming is already excluding, exclusion already threatening. Since language is the first indicator of the persistence of evil, its prophylactic auscultation is justified.

Political correctness fights less the evil in its fatal radicalism than its roots, its basic, subconscious, and still harmless banality. There is for this censorship in respect of its external politicization and performative understanding of utterances, no threshold or scale of evil. Political correctness "desubstantializes" evil to absolutize it better. For this double logic of absolutization and desubstantialization, evil becomes the object of an obsession in the belief that banality can revert into the worst, superficiality into barbarism, the exception into the rule. The politically correct man 
experiences the world in its inconsistency, a world in which humanity is about to succumb to its totalitarian temptations which he needs to purge.

In other terms, political correctness is the ideology of peaceful societies paradoxically haunted by their barbarism.

The refusal to consider peace as sustainable, the deep distrust toward the victory over evil generates a set of confusions and conflations which confirms its fears and gives them a political resonance. ${ }^{6}$ To that extent, the memory of great oppressions of minorities is copiously invoked in order to strategically support the thesis of their imminent return.

\section{The Double Non-Differentiation of the "We"}

The rejection of any differentiation motivates the ban of stereotyping, distinguishing, or naming a group since, as set out above, 'naming is already excluding, excluding already threatening' which means replaying the primal scene of majority oppression.

To prevent this risk, its strategy consists, besides censorship, in non-differentiation and individualization which is another form of non-differentiation: political correctness denies the 'collective you', the group, in favor of the 'individual you', as irreducible individual or abstract universal man, in order to integrate him into a fictitious ' $w e^{\prime}$ ', a non-differentiated majority. It represents an assimilation attempt of others by non-differentiation of the self. Thus non-differentiation and ban of the 'collective you', of naming and judging it, ultimately hide the non-differentiation and ban of the 'we'. In other words, otherness is denied to avoid any confrontation of an own identity with it.

The non-differentiation of the 'we' represents the ideological product of a double process of identity dissolution: a dissolution from the top under the impact of abstract universalism and his famous variations (such as human rightism cultural relativism, global citizenship, open-borders ideology, etc.) and from the bottom under the impact of contemporary individualism which reduces the perception and appreciation of others to their idiosyncrasy.

Therefore the integration ideal of political correctness corresponds less to an ideal of assimilation with the majority than a recognition of a common humanity, a conflation of man and human, person and individual. In other words, political correctness is the universalist individualism made morality and censorship.

\section{Identity Egalitarianism}

Political correctness takes part in a reversal of the principle of socio-economic equality into an identity egalitarianism which —needless to say-induces a deep redefinition of social justice.

Compared to the classical notion of inequality which refers to material, objective, and quantifiable differences and injustices, the notion of identity proves to be more complex because of its subjective, contextual, fluctuating and-in absolute terms-unfathomable dimensions. Applied to identity, the principle of equality raises the question of how to address inequalities, by which measure, institution, etc. The very purpose of equality becomes even more problematic: how to make an identity a political object and a subject? How to assess inequalities in terms of identity? On the basis of what criteria can the legitimacy of groups' claims, interlocutors, and representatives be judged? Should an 'identity protection' be conceived emulating the model of social protection?

The ideal of ethnic, gender, sexual, religious, and other non-differentiations as renunciation of an own and majority identity, represents the political other side of a collective guilty conscience, of a will to repent, leading to a contradictory thoughtfulness and deference towards minorities. This is the main contradiction of political correctness in that it forbids the full non-differentiation of the 'we' it aims at:

6 For example, in some European countries, simply using the word "races" will arouse the suspicion that you are a defender of racial order, of neo-colonialism, of ethnical discrimination, etc. That way, the suspicion increases the feeling of serious threat which inspires political correctness as censorship and activism. 
the fear of a possible oppression of minorities justifies their monopoly over identity differentiation which has been previously denied by self-censorship and false candor.

\section{A Victim Communitarianism}

By explicitly denying social diversity, by blinding oneself to the group's singularity, by prohibiting their naming, the consideration of their invariants, while implicitly encouraging minority claims, a system of privileges, the granting of censorship power over consciences through preferential treatment, political correctness contributes to communal fragmentation of society.

The communal instrumentalization of political correctness allows any group to establish itself as censor and object of censorship, to be judge and taboo object. It represents an opportunity for any minority to assert its existence, avoiding external designation and judgment, while annexing a part of the collective superego. The recognition of their status offers the dual benefits of 'minority immunity' and power of censorship.

This leads to the growing, individually or collectively, claim of minority status. By a "logic of reactivation of memories and mournings" (Camille Tarot [4]), it also creates mimetic rivalry between groups in form of victim one-upmanship.

In short, political correctness denies diversity to enhance its force of dissolution and allocation of blame.

\section{Conclusions-The Implosion of Politics}

The original intention of political correctness, namely the ban of libelous statements against certain groups or minorities, cannot be subjected to criticism in the name of Western world values. Its success and its mobilizing capacity lies in the incontestability of its premises which makes any criticism of political correctness highly suspect.

Nevertheless, political correctness promotes a logic of one-upmanship, intransigence, and obsessive suspicion of the worst. As such, it represents a new form of social radicalism clashing with the values it wants to preserve.

As freedom fighter political correctness in practice tends to excel in morale and repression. Preaching peaceful coexistence, it prohibits sociological thinking and, in that way, the understanding of each other as group members. The principles of equality and impartiality are perverted into favoritism and granting of new privileges within a neutralized, desubstantialized, tendentiously or explicitly incriminating majority. Considered an ideology of non-violence, political correctness blindly foments heterogeneous profusion of violence inherent in human groups.

If the political condition of man involves the delineation and recognition of an own sphere, the eclipse of the 'we' means the implosion of politics. In this sense, the opposition of political correctness to any designation of an enemy, even in time of war, is symptomatic of this implosion like the fact that its expansion is contemporary to a dissolution of politics into economics.

Since political correctness conveys a utopia of non-differentiation, it nurtures among men the illusion of a possible renunciation of their political condition and ultimately prevents them from guarding themselves against the founding violence of human communities.

Acknowledgments: Thanks to my sister and Walter Köppe for their assistance in the translation of this paper.

Conflicts of Interest: The author declares no conflict of interest.

\section{References}

1. Lorenzo, M. Political correctness between wise stoicism and violent hypocrisy. Philosophies 2017, 1, 261. [CrossRef]

2. Chaumont, J.M. Du culte des héros à la concurrence des victims. Criminologie 2000, 33, 167-183. Available online: erudit.org (accessed on 25 May 2017). [CrossRef] 
3. Esther, B. La concurrence des victims. In Culture Coloniale en France. De la Révolution Française à Nos Jours; Pascal, B., Sandrine, L., Nicolas, B., Eds.; CNRS Editions: Paris, France, 2008; pp. 585-594.

4. Tarot, C. Le Symbolique et le Sacré; La Découverte: Paris, France, 2008.

(C) 2017 by the author. Licensee MDPI, Basel, Switzerland. This article is an open access article distributed under the terms and conditions of the Creative Commons Attribution (CC BY) license (http://creativecommons.org/licenses/by/4.0/). 